\title{
Factors Affecting Hospital Readiness in Pandemic Situation: A Literature Review
}

\author{
Jenny Latief*, Syahrul Said, Kusrini S. Kadar \\ Faculty of Nursing, Hasanuddin University, Makassar, Indonesia \\ *jenny_latief@yahoo.com
}

\begin{abstract}
Comprehensive hospital readiness in facing the pandemic could reduce the spread of the virus, protect health care workersand provide optimal services during a pandemic. This literature review aims to identify the factors affecting the hospitals readiness in facing the pandemic. Literature search was performed using Ebsco Host, Pubmed, ScienceDirect and Proquest databases with inclusion and exclusion criteria in accordance with the literature objectives. Review made on articles and obtained seven research articles that qualify reviews. The research article reviewed showed that there were several factors affecting the hospitals readiness in facing the pandemic. The factors are the availability of pandemic preparedness planning system, the availability of guidelines and infection prevention and control tools, education, training or simulation in facing the pandemic, the availability of facilities (medical devices and isolation room), communication system during the pandemic, the availability of human resources and pandemic preparedness evaluation system. An assessment of the factors affecting hospital readiness in facing the pandemic was performed to identify the challenges faced by hospitals and determine further action to improve hospital readiness in facing the pandemic that might occur in the future.
\end{abstract}

Keywords: Hospitals, Barriers, Readiness, Preparedness, Pandemic 


\section{STRADA Jurnal Ilmiah Kesehatan}

DOI: $10.30994 /$ sjik.v9i2.331

ISSN: 2252-3847 (print); 2614-350X (online)

Vol.9 No.2 November 2020 Page. $478-480$

\section{BACKGROUND}

Infectious diseases are the third leading cause of death in the world (WHO, 2018). International mobility plays a role in the spread of pathogens leading to dangerous global pandemics and pose risks to the health of individuals and communities (Corless, et al., 2018). There are some pandemics in the twentieth century with intervals of 9 to 39 years. Spanish flu (H1N1) in the year 1918/19 was the most devastating pandemic and resulted in 25 million to 50 million deaths worldwide (Killingray \& Philips, 2001). Other pandemics occurred in 1957 (Asian Flu, H2N2), 1968 (Hong Kong Flu, H3N2), 1977 (Russian Flu, H1N1) (Palese, 2004 \& Skelton, 2006) and pandemic Covid-19 is the case today with morbidity and mortality experienced by the patient from respiratory failure (Yang, et al., 2020). Recent data show that infected as many as 4,307,287 inhabitants and 295,101 patients died from Covid-19 worldwide (WHO, 2020).

Besides the threat of morbidity and mortality, an influenza pandemic could affect the health care system. During the pandemic, Hospitals faced a particular challenge in ensuring the availability of medical devices and personal protective equipment (PPE) in providing services to patients that exceeded the hospital's capacity. In addition, during a pandemic, hospitals also face barriers in providing health professionals who provide services on an ongoing basis in all key areas due to transportation problems, responsibility of health care workers to care for sick family members, lack of knowledge of the staff about the risks or their role in the response to the pandemic occurrence and concern for their family or themselves while on duty (Hope, et al., 2010). Therefore, it takes a pandemic preparedness systems in hospitals to ensure the health and other vital systems continue to function during a pandemic (Department of Communicable Disease Surveillance and Response, 2004).

A comprehensive and realistic planning based on projections of the Centre for Disease Control (CDC) in each hospital and collaborative planning among all hospitals in an area can help in limiting the spread of virus to protect health care workers and retain health care workers in hospitals, protect non-infectious patients from infection, maintain the ability to provide health care for patients with non-infectious, reduce the workload of health care workers in hospitals by allocating health care resources are limited in a rational way, ethical, and organized to make optimum services to the increasing number of patients (Toner \& Waldhorn, 2020).

A comprehensive disaster preparedness strategy for the hospital consists of: Assessment of hazards, risks and vulnerabilities; Response mechanisms and strategies; Preparedness Planning; Coordination; Information management; Early warning system; Mobilization of resources; Education, training and simulation; and Community-based disaster preparedness (IFRC, 2000; Sutton \& Tierney, 2006; \& Sadeka et al., 2015).

Some studies show that some hospitals do not yet have the level of preparedness in facing the pandemic which is influenced by several factors such as; lack of hospital preparedness planning, lack of simulation in facing the pandemic, lack of negative pressure isolation room facilities and lack of planning and availability of human resources (HR) and logistics Hospitals (Personal Protective Equipment, Linen and laboratory equipment) (Reidy et al., 2015). While some factors that can increase hospital preparedness for a pandemic such as; provision of training and education about the pandemic, pandemic preparedness guidelines socialization continuously, evaluation of the implementation of pandemic preparedness to identify strengths and improve the weaknesses, the communication system between the government, hospital and health care 


\section{STRADA Jurnal Ilmiah Kesehatan}

DOI: $10.30994 /$ sjik.v9i2.331

ISSN: 2252-3847 (print); 2614-350X (online)

Vol.9 No.2 November 2020 Page.478-480

workers and to protect the health and welfare for health care workers(Adini, Laor, \& Aharonson-Daniel, 2014). Identification of the factors of hospital readiness in facing the pandemic is very important, so that the hospital can make efforts to improve preparedness for a pandemic. The purpose of this literature review is to identify the factors affecting the hospital readiness in facing the pandemic.

\section{METHODS}

Identification of the article about the factors affecting the hospitals readiness in facing the pandemic is done through electronic database by 591 articles ( Ebsco Host, $\mathrm{n}=$ 25; ScienceDirect, $n=467$; Pubmed, $n=65$; Proquest, $n=34$ ). The keywords used in the article search were: hospital; preparedness; readiness; challenge; barrier; pandemic; factors affected hospital in pandemic which is connected with "AND" dan "OR". Inclusion criteria for this literure is the full text articles in English, published in 2013-2020 and studies conducted in a hospital. Exclusion criteria are articles about disasters other than pandemics, articles in abstract form, literature review or books. The process of searching and selecting articles can be seen in Figure 1.

Figure 1. PRISMA Diagram of Article Search

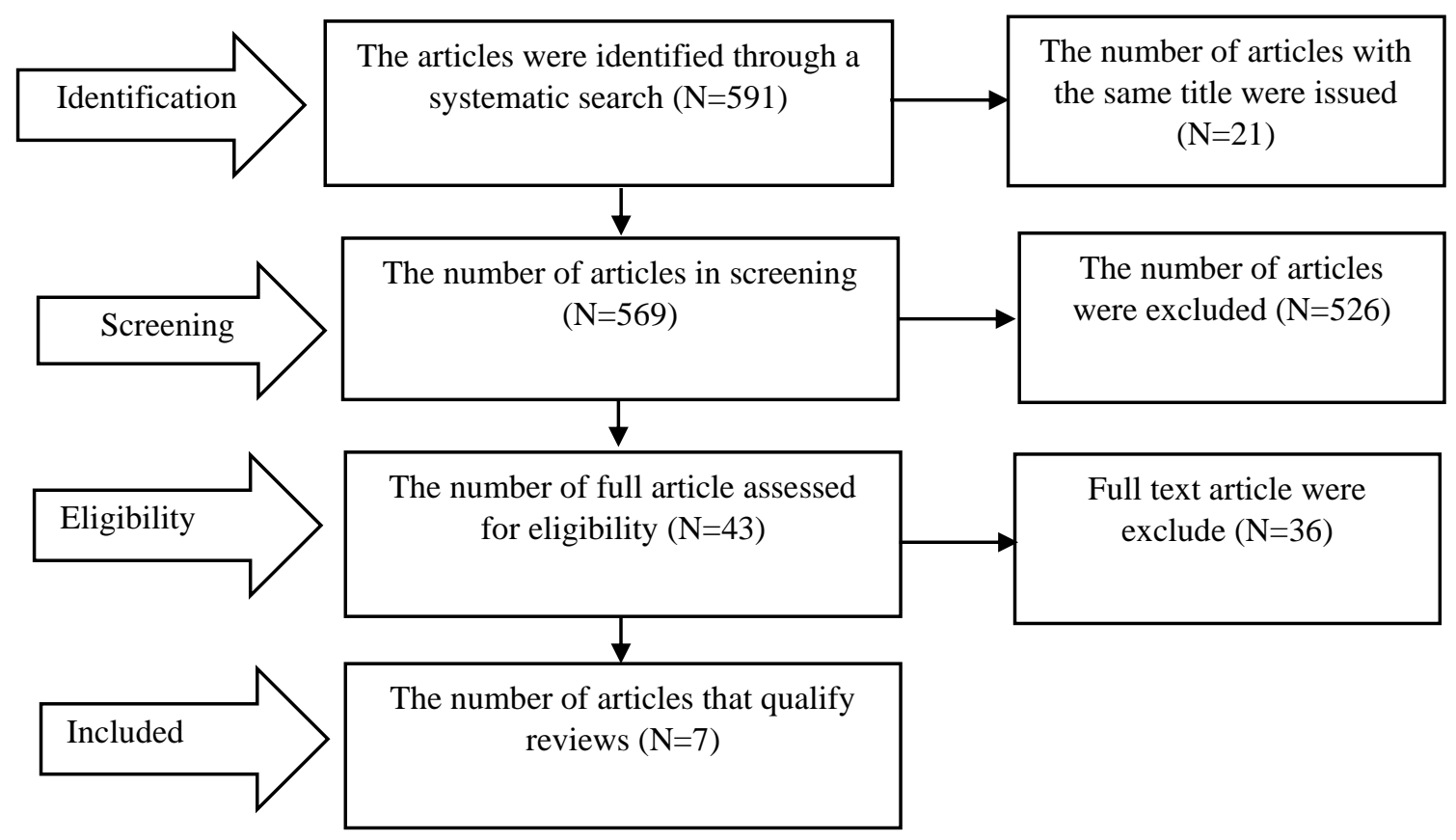

\section{RESULTS}

Based on literature search on five data based obtained 591 related studies. After screening the title and abstract, 486 articles were issued. After that the author reviewed the full text, 83 remaining articles to be evaluated in more detail. Then, 7 articles obtained (Table 1), which describes the factors affecting hospital readiness in facing the pandemic.

\section{DISCUSSION}

Preparedness can be defined as the ability to reduce morbidity and mortality resulting from large-scale spread of infectious diseases such as influenza pandemic, natural disasters or other human induced disasters (Nelson, Lurie, \& Wasserman, 2007). Based on the research 


\section{STRADA Jurnal Ilmiah Kesehatan}

DOI: $10.30994 /$ sjik.v9i2.331

ISSN: 2252-3847 (print); 2614-350X (online)

Vol.9 No.2 November 2020 Page.478-480

objectives which are reviewed, several factors affecting hospital readiness in facing the pandemic, as follows:

\section{Pandemic Preparedness Planning System}

Some studies conclude that the availability of pandemic preparedness planning system at the hospital can improve hospital preparedness for a pandemic (Reidy et al., 2015; Dewar et al., 2014; Adini et al., 2014; \& Kanwar et al., 2020). The purpose of pandemic planning is to help hospitals be ready to recognize and manage influenza pandemics. Planning can minimize the spread of the pandemic virus, reducing the cases, hospitalizations and deaths, as well as maintaining essential services in hospitals in order to keep it running during a pandemic (WHO, 2011). Hospital emergency management plan is a vital element of hospital preparedness for a large number of victims and the need to address all of the major risks including biological threats such as bioterrorism, infectious diseases, plague and pandemic (rebmann t., 2009). According to prescott et al., (2020), the preparedness system planning should be disseminated to all hospital staff so that all staff can know what to do in case of pandemic.

\section{Infection Prevention and Control System}

Health care workers willing to work during a pandemic related to their perception of the health risks and environmental safety work (Dionne et al., 2018). Hospital infection prevention and control systems include planning the vaccine and the availability of personal protective equipment during a pandemic. The risk of contracting during the work can be reduced by vaccination and the use of appropriate Personal Protective Equipment standards. As research (Rebmann et al., 2019; Reidy et al., 2015) which explains that health care workers are more willing to work if they or their family members are given the influenza vaccine and work using full Personal Protective Equipment because it can increase the security work during a pandemic. It is a challenge for the hospital because the vaccine was not available until the first wave of the pandemic passed so that early preventive action is done by providing a complete Personal Protective Equipment (Dewar, Barr, \& Robinson, 2014). Besides other challenges that occur during a pandemic is a shortage of Personal Protective Equipment supply in hospitals, therefore the hospital is responsible for the supply by identifying needs and recourse to the central or local governments.

\section{Education, Training and Simulations}

Education and training are factors increasing hospital preparedness in facing the pandemic (Dewar, Barr, \& Robinson, 2014; Adini, Laor, \& Aharonson-Daniel, 2014; Rebmann, et al., 2019). Knowledge of health personnel of a pandemic can be enhanced through education and training. As in research Adini, Laor, \& Aharonson-Daniel (2014), which states that the activities increasing knowledge and services during a pandemic simulations related to preparedness and capacity to respond to such an event. The training which is expected to be able to increase the readiness of hospitals and health care workersis training on how to use and release Personal Protective Equipment, training to screen patients and education about a pandemic disease (Kanwar et al., 2020) 


\section{STRADA Jurnal Ilmiah Kesehatan}

DOI: $10.30994 / \mathrm{sjik} . v 9 i 2.331$

ISSN: 2252-3847 (print); 2614-350X (online)

Vol.9 No.2 November 2020 Page.478-480

\section{Availability of Human Resources}

During the pandemic, the number of patients will exceed the amount of the availability of human resources in the hospital. Therefore, one of the factors influencing hospital readiness in facing the pandemic is the ability of the hospital to ensure the availability of human resources, especially health care workers. Dewar, Barr, \& Robinson (2014) and Dionne et al., (2018) stated that the absence of staff during a pandemic influenza related to their perception of the risks associated with personal health, family and the security of the working environment. Efforts to be made by the hospital to maintain the resource during pandemic is to provide employment protection (Personal Protective Equipment availability and isolation care facilities), provide health insurance for the provision of vaccines and treatment if infected and the clear allocation of roles and tasks during a pandemic as well as transport facilities from home to hospital. 


\section{Table 1: Characteristics of articles reviewed}

\section{Researcher/}

\section{Year}

Reidy et al., Preparedness of Hospitals Assess the readiness of (2015) in the Republic of Ireland hospitals in the Republic of for an Influenza Pandemic, Ireland for an influenza an Infection Control pandemic from an infection Perspective control perspective.

Dewar et al., Hospital capacity and Assessing the readiness of (2014) management preparedness hospitals in Victoria, for pandemic influenza in Australia, for influenza Victoria pandemic events, especially focusing on disaster planning and management efforts. preparedness and capacity to manage pandemic
Identifying factors influencingQuasi-

Experiment
Research

methods
Cross

Sectional

Mix Method n: 56 Hospitals in Hospital readiness in facing the pandemic from an infection Ireland control perspective shows that the lack of hospital preparedness planning, lack of simulation in facing the pandemic, lack of negative pressure isolation room facilities and lack of planning and availability of human resources and hospital logistics in a pandemic (Personal Protective Equipment, linen and laboratory equipment)

n: 43 hospitals in - Country Hospitals show a higher level of staff planning during the pandemic than urban hospitals (comparison of $60 \%$ and $40 \%$, respectively).

- All hospitals have a preparedness planning system and only $60 \%$ of the hospitals conduct training or simulations in facing the pandemic.

- All hospitals reported having a standard infection prevention and hand hygiene.

- - Only $33 \%$ of hospitals are able to provide services during a pandemic due to the high number of staff absences during the pandemic.

- The challenges experienced by hospitals during a pandemic such as the lack of medical equipment (ventilators), Personal Protective Equipment, medicines and N95 mask supplies and the slowness of examination results

- The communications system during a pandemic it is important to receive, coordinate and distribute internal and external information.

n: 28 hospitals in - $91 \%$ of hospital leaders assess that their hospitals are ready or very ready to deal with an influenza pandemic and as many as $87 \%$ of hospitals are considered capable of serving influenza 
influenza: perceptions of pandemic by assessing healthcare managers perceptions of hospital managers about

measures implemented to promote readiness to deal with influenza pandemic; assessing the readiness and ability of hospitals to manage influenza pandemics; and the effectiveness of the national pandemic preparedness program in Israel

Rebmann, et Emergency Medical al., (2019) Services Personnel's Pandemic Influenza Identification of the determinants of the Quantitative n: 522 paramedic Survey willingness of Emergency

Training Received and Medical Services (EMS)

Willingness to Work personnel to work during an During a Future Pandemic influenza pandemic.

Dionne et al., Health Care Workers' Risk Assessing the relationship (2018) Perceptions and between perceptions of

Willingness to Report for personal health risks and Work during an Influenza occupational risks with Pandemic willingness to work during an influenza pandemic. pandemic patients

factors affecting the readiness of hospitals is the availability of pandemic preparedness guidelines and implemented nationally in Israel, pandemic education to health workers, simulating a pandemic preparedness, socializing pandemic preparedness guidelines continuously, evaluating the implementation of pandemic preparedness, providing a communication system between the government, hospital and health care workers can reduce stress levels of health workers, and to protect the health and welfare to health workers.

$\begin{array}{ll}\text { Quantitative } & \mathrm{n}: \\ \text { Survey } & \begin{array}{l}3971 \text { medic and } \\ \text { paramedic }\end{array}\end{array}$

Health care workers are willing to work during a pandemic if needed $(88.2 \%)$

- Health care workers are willing to work during a pandemic if they or their family members are given a vaccine and a safe working environment.

- Training and planning before a pandemic occurs, pandemic management simulations, Personal Protective Equipment availability and training on how to use Personal Protective Equipment increases the willingness of health care worker to work during a pandemic

$50 \%$ of health care workers reported that organizational factors affect the trend of health care workers to work during a pandemic is the availability of facilities, a clear tasks and role of health professionals and transportation facilities during a pandemic

- Barriers to the willingness of health care workers to work during a pandemic, among others; fear of infection and transmission to family members, responsibility for caring for other family members and inadequate availability of infection prevention and control facilities (PPI) 
(2020)

Preparedness Among

Hospitals in Idaho hospitals to treat suspected Sectional patients and patients with confirmed positive COVID-

19

Prescott et al., COVID-19: how prepared Assessing health care workers Cross

(2020) are front-line healthcare perceptions about trust and Sectional workers in England? of readiness to deal with

Covid-19 cases in hospitals.
Idaho, USA

disaster preparedness system, infection control programs, the availability of disaster command structures, occupational health and safety system, training of staff in the screening of patients with respiratory symptoms including Covid-19, the provision of Personal Protective Equipment for health professionals and patients, Covid-19 patient-specific treatment available space, patient evacuation routes are available and PPI guidelines are applied according to CDC standards

n: 158 health care - Education and training of health care workers will increase the worker in confidence of health workers

hospitals, England - Education and training are necessary for health care workers prepared for a pandemic include training on PPI, education how to use and disposal of Personal Protective Equipment and training on sampling and diagnostic examinations

Up-to-date information systems and sources reduce anxiety and optimize the performance of health workers. 


\section{STRADA Jurnal Ilmiah Kesehatan}

DOI: $10.30994 /$ sjik.v9i2.331

ISSN: 2252-3847 (print); 2614-350X (online)

Vol.9 No.2 November 2020 Page.478-480

\section{Availability of Facilities}

The availability of better facilities for patients and health professionals is one of the factors for assessing hospital readiness in facing the pandemic. Kanwar et al., (2020) describes the facilities required during a pandemic is mask at each hospital entrance for visitors, information board about the procedures for infection control, isolation treatment rooms and a special line for isolation patient. In line with research Reidy et al., (2015) which explained that during a pandemic hospitals require a negative pressure isolation room to accommodate the needs of a pandemic patient care

Dewar, Barr, \& Robinson (2014) explained that in addition to health facilities (ventilators), Personal Protective Equipment, and medicine, hospitals also need to pay attention to laboratory facilities. Laboratory facilities are needed to determine the patient sample examination. Delay in lab results can create delays in clinical decision making and hampers the treatment of patients.

\section{Communication System}

Research by Dewar et al., (2014) \& Adini et al., (2014) indicate that the communication system between the hospital management and staff is essential to achieve and sustain the response to the pandemic. In addition, effective communication is another strategy to reduce the absence of health care workers during a pandemic. The communication process during a pandemic can be improved by determining the coordinator to receive, coordinate and distribute internal and external information. Research conducted by Dewar et al., (2014) indicates that the communication system is influenced by the geographical system of the hospital, where the communication system for hospitals in urban areas is felt more quickly than hospitals in the region.

\section{Evaluation System}

Research by Adini, Laor, \& Aharonson-Daniel (2014) explained that preparedness for an influenza pandemic was highly correlated with preparedness evaluation. Evaluations were conducted at two hospitals in the study revealed that the level of emergency preparedness for biological threats increased over time obtained from the evaluation process itself because of ongoing readiness to facilitate the more effective emergency mechanism. Evaluation of preparedness was found to contribute to the ability to manage influenza pandemic. During influenza pandemic occurs, the hospital management to prioritize preparedness to manage emergency scenarios and conduct an evaluation to identify strengths and weaknesses that should be corrected

\section{CONCLUSION}

Several factors that influence the readiness of hospitals in dealing with a pandemic have been identified in this literature review. The availability of pandemic preparedness system planning in hospitals is a major factor that must be prepared by hospitals before a pandemic occurs. Furthermore, the hospital must evaluate the implementation of the pandemic preparedness system before, during and after the pandemic so that the hospital can continue to improve its services during the pandemic. An assessment of the factors influencing hospital preparedness in dealing with a pandemic is carried out to identify the challenges faced by the hospital in dealing with a pandemic and actions that can be taken to improve hospital preparedness in the face of a pandemic that may occur in the future. 


\section{STRADA Jurnal Ilmiah Kesehatan}

DOI: $10.30994 /$ sjik.v9i2.331

ISSN: 2252-3847 (print); 2614-350X (online)

Vol.9 No.2 November 2020 Page. $478-480$

\section{REFERENCES}

Adini, B., Laor, D., \& Aharonson-Daniel, L. (2014). Factors Affecting Preparedness and Capacity to Manage Pandemic Influenza: Perceptions of Healthcare Managers. Public Health: 703-708. Http://dx.doi.org/10.1016/j.puhe.2014.06.002.

Corless, I. B., Nardi, D., Milstead, J. A., Kurth, A. E., Larson, E., Nokes, K. M., . . . Woith, W. (2018). Expanding Nursing's Role in Responding to Global Pandemics. Nursing Outlook: Vol. 66. Issue 4. Page 412-415. DOI: https://doi.org/10.1016/j.outlook.2018.06.003.

Department of Communicable Disease Surveillance and Response. (2004). Informal Consultation on Influenza Pandemic Preparedness in Countries with Limited Resources. Kuala Lumpur (MYS): World Health Organization. Retrieved form: https://apps.who.int/iris/bitstream/handle/10665/69822/WHO_CDS_CSR_GIP_2004 _1_eng.pdf?sequence $=1$.

Dewar, B., Barr, I., \& Robinson, P. (2014). Hospital Capacity and Management Preparedness For Pandemic Influenza In Victoria. Australian and New Zealand Journal of Public Health: 38:184-90. DOI: 10.1111/1753-6405.12170.

Dionne, G., Desjardins , D., Lebeau, M., Messier, S., \& Dascal, A. (2018). Health Care Workers' Risk Perceptions and Willingness to Report for Work during an Influenza Pandemic. Risks: 6 (1).DOI: https://doi.org/10.3390/risks6010008.

Hope, K., Durrheim, D., Barnett, D., D'Este,, C., Kewley, C., Dalton, C., . . . Links, L. (2010). Willingness of Frontline Health Care Workers to Work During A Public Health Emergency. Australian Journal of Emergency Management: 39-47. Retrieved from: https://jhu.pure.elsevier.com/en/publications/willingness-of-frontline-healthcare-workers-to-work-during-a-pub-3.

IFRC. (2000). Introduction to Disaster Preparedness. International Federation of Red Cross and Red Crescent Societies. Diakses pada: http://www.ifrc.org/Global/Introdp.pdf.

Kanwar, A., Heppler, S., Kanwar, K., \& Brown, C. K. (2020). A Survey of COVID-19 Preparedness Among Hospitals in Idaho. Infection Control \& Hospital Epidemiology: 1-8. DOI: https://doi.org/10.1017/ice.2020.218.

Killingray, D., \& Philips, H. (2001). The Spanish Influenza Pandemic of 1918-19: New Perspectives. London, UK: Routledge Press.

Nelson, C., Lurie, N., \& Wasserman, J. (2007). Assessing Public Health Emergency Preparedness: Concepts, Tools, and Challenges. Annual Review of Public Health: 118. DOI: https://doi.org/10.1146/annurev.publhealth.28.021406.144054.

Prescott, K., Baxter, E., Lynch, C., Jassal, S., Bashir, A., \& Gray, J. (2020). COVID-19: How Prepared are Front-Line Healthcare Workers in England?. The Healthcare Infection Society: 142-145. DOI: https://doi.org/10.1016/j.jhin.2020.04.031.

Rebmann, T. (2009). APIC State-of-the-Art Report: The Role Of The Infection Preventionist In Emergency Management. American Journal of Infection Control: 271-281. DOI: https://doi.org/10.1016/j.ajic.2008.12.002.

Rebmann, T., Charney, R., Loux, T., Turner, J., Abbyad, Y., \& Silvestors, M. (2019). Emergency Medical Services Personnel's Pandemic Influenza Training Received and Willingness to Work During a Future Pandemic. Prehospital Emergency Care: 1-14. DOI: 10.1080/10903127.2019.1701158. 


\section{STRADA Jurnal Ilmiah Kesehatan}

DOI: $10.30994 /$ sjik.v9i2.331

ISSN: 2252-3847 (print); 2614-350X (online)

Vol.9 No.2 November 2020 Page. $478-480$

Reidy, M., Ryan, F., Hogan, D., Lacey , S., \& Buckley, C. (2015). Preparedness of Hospitals in the Republic of Ireland for an Influenza Pandemic, an Infection Control Perspective. BMC Public Health, doi: 10.1186/s12889-015-2025-6.

Sadeka, S., Reza, M., Mohamad, M. S., Manap, J., \& Sarkar, M. S. (2015). Social Capital and Disaster Preparedness: Conceptual Framework and Linkages. Social Science Research. DOI: 10.13140/RG.2.1.26644.9767.

Sutton, J., \& Tierney, K. (2006). Disaster Preparedness: Concepts, Guindance and Research. Colorado: University of Colorado. Retrieved from: http://www.fritzinstitute.org/pdfs/whitepaper/disasterpreparednessconcepts.pdf.

Toner, E., \& Waldhorn, R. (2020, February 27). Clinicians' Biosecurity News. Retrieved from:

http://www.centerforhealthsecurity.org/cbn/2020/cbnreport-02272020.html.

WHO. (2011). Pandemic Influenza Preparedness Framework for The Sharing ff Influenza Viruses and Access to Vaccines and Other Benefits. Geneva: WHO Press. Retrieved from: http://www.who.int/about/licensing/copyright_form/en/index. html).

WHO. (2018). The Top 10 Causes of Death. Media Centre. Retrieved from: https://www.who.int/news-room/fact-sheets/detail/the-top-10-causes-of-death.

WHO. (2020). Coronavirus disease (COVID-19) Pandemic. Retrieved from: https://www.who.int/southeastasia/outbreaks-and-emergencies/novel-coronavirus2019

Yang, X., Yu, Y., Xu, J., Shu, H., Xia, J., Liu, H., . . Shang, Y. (2020). Clinical Course and Outcomes of Critically Ill Patients With SARS-Cov-2 Pneumonia in Wuhan, China: A Single-Centered, Retrospective, Observational Study. The Lancet Respiratory Medicine. Doi: 10.1016/s2213-2600(20)30079-5. 